\title{
Pattern and risk factors of non-fistulous urinary incontinence among gynaecological clinic attendees in a Nigeria tertiary health institution
}

\author{
Charles O. Njoku ${ }^{1 *}$, Amarachukwu N. Njoku², Cajethan I. Emechebe ${ }^{1}$, Andrew E. Okpe ${ }^{1}$, \\ Christopher I. Iklaki ${ }^{1}$
}

${ }^{1}$ Department of Obstetrics and Gynecology, University of Calabar, Calabar, Nigeria
${ }^{2}$ Department of Obstetrics and Gynecology, University of Calabar Teaching Hospital, Calabar, Nigeria

Received: 27 March 2020

Accepted: 29 April 2020

*Correspondence:

Dr. Charles O. Njoku,

E-mail: charlesnjokuobinna@gmail.com

Copyright: (c) the author(s), publisher and licensee Medip Academy. This is an open-access article distributed under the terms of the Creative Commons Attribution Non-Commercial License, which permits unrestricted non-commercial use, distribution, and reproduction in any medium, provided the original work is properly cited.

\begin{abstract}
Background: Urinary incontinence is the involuntary loss of urine. It is rarely disclosed by the patients and usually under-reported. Objective of this study was to determine the prevalence, pattern and risk factors of non-fistulous urinary incontinence among women attending gynaecological clinics in Calabar, Nigeria.

Methods: This was a cross-sectional study of 658 women attending gynecological clinic from June 2018 to June 2019. English version of International consultation on incontinence questionnaire-urinary incontinence-short form (ICIQ-UI-SF) was used to obtain data. Statistical analysis was done using SPSS version 22.

Results: The prevalence of urinary incontinence was $16.1 \%$. Stress incontinence was the commonest of urinary incontinence $(73.3 \%)$, other types were urge incontinence $(17.2 \%)$ and mixed incontinence $(9.5 \%)$. Independent risk factors for urinary incontinence were 40 years and above $(\mathrm{AOR}=5.610 ; \mathrm{p}<0.001)$, parity $\geq 3(\mathrm{AOR}=4.454$; $\mathrm{p}<0.001)$, lower educational level (primary) $(\mathrm{AOR}=2.588$; $\mathrm{p}<0.001)$, vaginal/instrumental deliveries $(\mathrm{AOR}=4.358$; $\mathrm{p}<0.001)$, carrying heavy load $(\mathrm{AOR}=3.688 ; \mathrm{p}<0.001)$ and farming $(\mathrm{AOR}=3.510 ; \mathrm{p}<0.001)$.

Conclusions: Non-fistulous urinary incontinence is common among women in our environment. Stress urinary incontinence was the most common type. Advanced age, higher parity, vaginal and instrumental deliveries and farming were independent risk factors for urinary incontinence.
\end{abstract}

Keywords: Prevalence, Risk factors, Types, Urinary incontinence

\section{INTRODUCTION}

Urinary incontinence is an involuntary loss of urine, which impacts negatively on women's psychosocial health and quality of life. ${ }^{1}$ Although urinary incontinence in Nigeria is often attributed to vesicovaginal fistula because of high prevalence of obstetric fistula, nonfistulous types of urinary incontinence such as stress incontinence, urge incontinence and mixed incontinence have been under-reported..$^{2-4}$ Ijaiya et al found a prevalence of $30.6 \%$ among family planning clinic attendees in south-west Nigeria, Okunola et al reported $28.1 \%$ among pregnant women in south-west Nigeria and Adaji et al found $21.1 \%$ among antenatal clients in northern Nigeria. ${ }^{3-5}$ Notwithstanding, non-fistulous urinary incontinence is often given less attention in Nigeria as women who suffer this condition rarely seek treatment; this is because some women with this condition see it as normal aging process, others are held back by social stigma associated with it. ${ }^{5}$ In a study of women attending general outpatient clinic in south-west Nigeria, $73.8 \%$ of women with urinary incontinence did not consider it a reason to present to hospital. ${ }^{6}$

Reported risk factors associated with non-fistulous incontinence include vaginal delivery, multiparity, previous history of instrumental delivery, obesity and third trimester of pregnancy. 
Urinary incontinence is classified into three types: stress incontinence, when it occurs with increase intraabdominal pressure (coughing, sneezing, physical exercise); urge incontinence, when associated with urinary urgency; mixed incontinence, when stress and urge incontinence co-exist in a patient. ${ }^{1}$

Urinary incontinence affects women's quality of life in several aspects mainly social, psychological and sexual. ${ }^{4,5}$ It is often associated with loss of self-esteem, stigmatization and poor social acceptability especially in Africa where women are culturally and traditionally disadvantaged by gender inequality. 8,9 Therefore, this study is aimed at determining the prevalence, types and risk factors of non-fistulous urinary incontinence among patients attending gynaecological clinics of the University of Calabar teaching hospital, Calabar, Nigeria. Determining the magnitude and risk factors of this condition in our environment will enhance awareness of this condition, inform preventive measures to reduce the prevalence and provide data for health managers on effective distribution of health resources for treatment of existing cases.

\section{METHODS}

\section{Design and data collection}

This cross-sectional study included 658 women attending gynecological clinic between $8^{\text {th }}$ June 2018 and $7^{\text {th }}$ June 2019. Study population comprised gynecological patients. Inclusion criterion was patients with gynecological complaints while exclusion criteria were patients with urogenital fistula, pregnant women, physical disability and patient suffering from severe mental diseases. Ethical approval for the study protocol was obtained from the Ethics Committee of the University of Calabar Teaching Hospital, Calabar. Informed consents were obtained from all patient prior to the interviews. The study participants were screened for urinary incontinence, using International consultation on incontinence questionnaire-urinary incontinence-short form (ICIQ-UISF) English version. Weight and height of all participants were taken and body-mass index (BMI) calculated. For participants with urinary incontinence, vaginal examination was done to exclude urogenital fistula.

\section{Measures \\ Incontinence questionnaire-short form (ICIQ-UI-SF)}

It was designed to assess presence and type of urinary incontinence. It evaluates how often does urinary leakage occurs, quantity of urinary leakage, how much does urinary leakage interfere with daily life, when does urinary leakage occurs.

\section{Demographic questionnaire}

This included item on age, parity, educational level, occupation, mode of delivery and history of carrying heavy load.

\section{Statistical analysis}

SPSS statistics program (IBM Corp. version 22) was used for data analysis. Statistical comparison was done using Chi-square $\left(\mathrm{X}^{2}\right)$ test and odd ratio at level of significance $\mathrm{p}$ value was taken at $\mathrm{p}<0.05$.

\section{RESULTS}

Out of the 658 participants, 106 women experienced urinary incontinence, giving a prevalence rate of $16.1 \%$. Figure 1 shows that stress incontinence $(73.3 \%)$ was the commonest type of urinary incontinence, followed by urge urinary incontinence $(17.2 \%)$ and mixed incontinence $(9.5 \%)$.

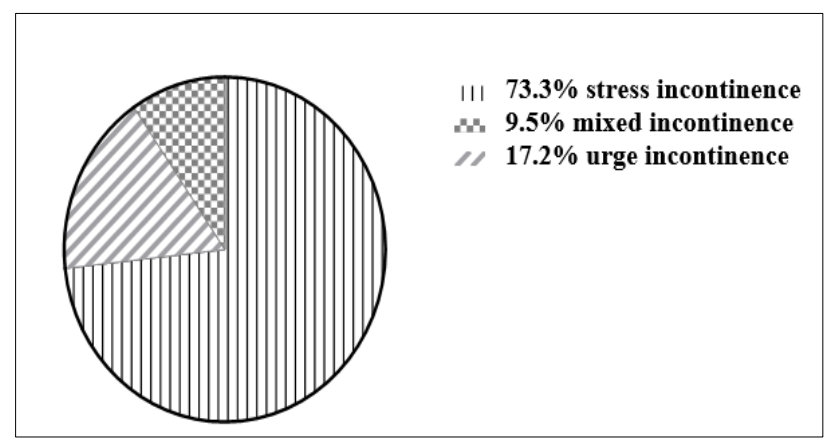

Figure 1: Types of urinary incontinence.

Table 1: Risk factors for urinary incontinence.

\begin{tabular}{|c|c|c|c|c|c|c|}
\hline Variables & Total & Inc & ce present $(\%)$ & \multicolumn{2}{|c|}{ Incontinence absent (\%) } & p-value \\
\hline \multicolumn{7}{|c|}{ Age (years) } \\
\hline$\leq 19$ & 18 & 0 & $0.0 \%$ & 18 & $100 \%$ & \multirow{5}{*}{$\begin{array}{l}X^{2}=97.09 \\
p<0.001 *\end{array}$} \\
\hline $20-29$ & 166 & 12 & $7.2 \%$ & 154 & $92.8 \%$ & \\
\hline $30-39$ & 214 & 10 & $4.7 \%$ & 204 & $95.3 \%$ & \\
\hline $40-49$ & 144 & 36 & $25.0 \%$ & 108 & $75.0 \%$ & \\
\hline$\geq 50$ & 116 & 48 & $41.4 \%$ & 68 & $58.6 \%$ & \\
\hline \multicolumn{7}{|c|}{ Body mass index (BMI) } \\
\hline$<30$ & 348 & 54 & $15.5 \%$ & 294 & $84.5 \%$ & $X^{2}=0.1917$ \\
\hline
\end{tabular}




\begin{tabular}{|c|c|c|c|c|c|c|}
\hline \multirow{2}{*}{$\begin{array}{l}\text { Variables } \\
\geq 30\end{array}$} & \multirow{2}{*}{$\begin{array}{l}\text { Total } \\
310\end{array}$} & \multicolumn{2}{|c|}{ Incontinence present (\%) } & \multicolumn{2}{|c|}{ Incontinence absent (\%) } & \multirow{2}{*}{$\begin{array}{l}p \text {-value } \\
p<0.662\end{array}$} \\
\hline & & 52 & $16.8 \%$ & 258 & $83.2 \%$ & \\
\hline \multicolumn{7}{|l|}{ Educational level } \\
\hline Primary & 70 & 18 & $25.7 \%$ & 52 & $74.3 \%$ & \multirow{3}{*}{$\begin{array}{l}X^{2}=17.51 \\
p<0.001^{*}\end{array}$} \\
\hline Secondary & 150 & 36 & $24.0 \%$ & 114 & $76.0 \%$ & \\
\hline Tertiary & 438 & 52 & $11.9 \%$ & 386 & $88.1 \%$ & \\
\hline \multicolumn{7}{|l|}{ Parity } \\
\hline 0 & 234 & 4 & $1.7 \%$ & 230 & $98.3 \%$ & \multirow{4}{*}{$\begin{array}{l}X^{2}=164.2 \\
p<0.001 *\end{array}$} \\
\hline $1-2$ & 190 & 14 & $7.4 \%$ & 176 & $92.6 \%$ & \\
\hline $3-4$ & 190 & 58 & $30.5 \%$ & 132 & $69.5 \%$ & \\
\hline$\geq 5$ & 44 & 30 & $68.2 \%$ & 14 & $31.8 \%$ & \\
\hline \multicolumn{7}{|l|}{ Mode of delivery } \\
\hline Vaginal & 298 & 82 & $27.5 \%$ & 216 & $72.5 \%$ & \multirow{3}{*}{$\begin{array}{l}X^{2}=19.77 \\
p<0.001 *\end{array}$} \\
\hline Caesarean section & 68 & 2 & $2.9 \%$ & 66 & $97.1 \%$ & \\
\hline Instrumental deliveries & 60 & 18 & $30.0 \%$ & 42 & $70.0 \%$ & \\
\hline \multicolumn{7}{|l|}{ Carrying heavy load } \\
\hline Yes & 54 & 36 & $66.7 \%$ & 18 & $33.3 \%$ & \multirow{2}{*}{$\begin{array}{l}X^{2}=111.3 \\
p<0.001^{*}\end{array}$} \\
\hline No & 604 & 70 & $11.6 \%$ & 534 & $88.4 \%$ & \\
\hline \multicolumn{7}{|l|}{ Occupation } \\
\hline Artisans & 90 & 18 & $20.0 \%$ & 72 & $80.0 \%$ & \multirow{5}{*}{$\begin{array}{l}X^{2}=119.4 \\
p<0.001^{*}\end{array}$} \\
\hline Farmers & 32 & 26 & $81.3 \%$ & 6 & $18.7 \%$ & \\
\hline Housewives & 42 & 6 & $14.3 \%$ & 36 & $85.7 \%$ & \\
\hline Public/civil servant & 360 & 52 & $14.4 \%$ & 308 & $85.6 \%$ & \\
\hline Traders & 134 & 4 & $3.0 \%$ & 130 & $97.0 \%$ & \\
\hline
\end{tabular}

Table 2: Multivariate analysis of risk factors for urinary incontinence.

\begin{tabular}{|c|c|c|c|}
\hline Variables & Adjusted odds ratio & $95 \% \mathrm{CI}$ & p-value \\
\hline \multicolumn{4}{|l|}{ Age (years) } \\
\hline$<40$ & 1 & \multirow{2}{*}{5.337 to 5.882} & \multirow{2}{*}{$<0.001 *$} \\
\hline$\geq 40$ & 5.610 & & \\
\hline \multicolumn{4}{|l|}{ Body mass index } \\
\hline$<30$ & 1 & \multirow{2}{*}{-2.294 to 6.585} & \multirow{2}{*}{0.341} \\
\hline$\geq 30$ & 2.157 & & \\
\hline \multicolumn{4}{|l|}{ Parity } \\
\hline$\leq 2$ & 1 & \multirow{2}{*}{4.227 to 4.665} & \multirow{2}{*}{$<0.001 *$} \\
\hline$\geq 3$ & 4.454 & & \\
\hline \multicolumn{4}{|l|}{ Educational level } \\
\hline Secondary/tertiary & 1 & \multirow{2}{*}{1.991 to 3.100} & \multirow{2}{*}{$<0.001 *$} \\
\hline Primary & 2.588 & & \\
\hline \multicolumn{4}{|l|}{ Mode of delivery } \\
\hline Caesarean section & 1 & \multirow{2}{*}{4.126 to 4.574} & \multirow{2}{*}{$<0.001 *$} \\
\hline Vaginal/instrumental deliveries & 4.358 & & \\
\hline \multicolumn{4}{|l|}{ Carrying heavy load } \\
\hline No & 1 & \multirow{2}{*}{3.497 to 3.879} & \multirow{2}{*}{$<0.001 *$} \\
\hline Yes & 3.688 & & \\
\hline \multicolumn{4}{|l|}{ Occupation } \\
\hline Others & 1 & \multirow{2}{*}{3.274 to 3.745} & \multirow{2}{*}{$<0.001 *$} \\
\hline Farmers & 3.510 & & \\
\hline
\end{tabular}

Table 1 illustrates the risk factors for urinary incontinence. Urinary incontinence was higher among women that were 50 years and above $(41.4 \%)$ compared to other age groups $(\mathrm{p}<0.001)$. Other risk factors were lower level education: primary education (25.7\%) and secondary education $(24.0 \%)(\mathrm{p}<0.001)$; high parity: para $3-4(30.5 \%)$ and para 5 and above $(68.2 \%)(\mathrm{p}<0.001)$; vaginal delivery $(27.5 \%)$ and instrumental delivery 
$(30.0 \%) \quad(\mathrm{p}<0.001) ;$ carrying heavy load $(66.7 \%)$ $(\mathrm{p}<0.001)$ and farming $(81.3 \%)(\mathrm{p}<0.001)$.

Table 2 showed the multivariate analysis of the risk factors. Women that were 40 years and above had about five times risk of urinary incontinence ( $\mathrm{AOR}=5.610$; $\mathrm{p}<0.001)$. Other risk factors: parity $\geq 3 \quad(\mathrm{AOR}=4.454$; $\mathrm{p}<0.001$ ), lower educational level (primary) $(\mathrm{AOR}=2.588 ; \mathrm{p}<0.001)$, vaginal/instrumental deliveries $(\mathrm{AOR}=4.358 ; \quad \mathrm{p}<0.001)$, carrying heavy load $(\mathrm{AOR}=3.688 ; \mathrm{p}<0.001)$ and farming $(\mathrm{AOR}=3.510$; $\mathrm{p}<0.001)$ had higher odds of urinary incontinence.

\section{DISCUSSION}

Urinary incontinence is a public health issue that has negative impact on women's psychosocial health. ${ }^{4,9}$ The prevalence of non-fistulous urinary incontinence in this study was $16.1 \%$, which is lower than $30.6 \%$ in Ilorin, south-west Nigeria, $28.1 \%$ in Ekiti, south-west Nigeria and $21.1 \%$ in northern Nigeria. ${ }^{3-5}$ However, it is higher than $5.2 \%$ reported among women attending general outpatient in Ile-Ife, Nigeria. ${ }^{6}$ The possible reason for the differences in prevalence could be attributed to difference in study populations and socio-cultural diversities in the populations investigated.

Stress incontinence was the commonest type of incontinence in this study. This finding is similar to the pattern reported from previous studies in Nigeria., ${ }^{3,5,6}$ However, Akkus et al in Turkey found that mixed incontinence was the main type of incontinence in their environment. ${ }^{10}$ This could be due to diversity of risk factors in different environment.

In the present study, women that were 40 years and above had five times higher risk of urinary incontinence. This is line with findings from previous studies. ${ }^{11,12}$ Age related changes in the bladder play a significant role in the pathogenesis of urinary incontinence. ${ }^{13}$

Lower level of education was an independent risk factor for urinary incontinence in this study. This finding is similar to reports of previous studies. ${ }^{12,14}$ This may be due to the positive influence of education on utilization of health facility for antenatal care, hospital delivery and low parity common among more educated women than less educated women. ${ }^{15}$

Women with previous history of vaginal delivery and instrumental vaginal delivery had more than four times odd for urinary incontinence in the present study. Ijaiya et al reported similar finding. ${ }^{5}$ Women with three or more deliveries had greater than four times risk for urinary incontinence in this study. The explanation for these could be subtle changes in the neuromuscular structures of the pelvic floor following vaginal delivery and the cumulative effect of these changes with repeated vaginal deliveries, affecting the sphincteric nerve control of the urethra and the pelvic floor muscles.
In the present study, history of carrying heavy load and farming were independent risk factors for urinary incontinence These activities increase the intraabdominal pressure, which displaces the bladder neck, resulting in stress urinary incontinence.

\section{CONCLUSION}

In conclusion, this study shows that non-fistulous urinary incontinence is common among women in our environment. Stress incontinence is the commonest type. It is associated with advance age and modifiable risk factors like low educational level, high parity, vaginal/ instrumental deliveries and farming. There is need to increase awareness and health education especially on the risk factors. Family planning, education and women empowerment are preventive strategies to reduce this distressing condition. There is need for further research, especially community-based studies to determine the impact of urinary incontinence on quality of life of women.

\section{Funding: No funding sources}

Conflict of interest: None declared

Ethical approval: The study was approved by the Institutional Ethics Committee

\section{REFERENCES}

1. Lukacz ES, Santiago-Lastra Y, Albo ME, Brubaker L. Urinary incontinence in women: a review. JAMA. 2017;318:1592-604.

2. Waaldijk K, Armiya'u YD. The obstetric fistula: a major public health problem still unsolved. Int Urogynecol J. 1993;4:126-8.

3. Okunola TO, Olubiyi OA, Omoya S, Rosiji B, Ajenifuja KO. Prevalence and risk factors for urinary incontinence in pregnancy in Ikere-Ekiti, Nigeria. Neurourol Urodyn. 2018;37:2710-16.

4. Adaji SE, Shittu OS, Bature SB, Nasir S, Olatunji O. Suffering in silence: pregnant women's experience of urinary incontinence in Zaria, Nigeria. Eur J Obstet Gynecol Reprod Biol. 2010;150:19-23.

5. Ijaiya MdA, Raji HO, Aboyeji AP, Adesina KT, Adebara IO, Ezeoke GG. Non-fistulous urinary leakage among women attending a Nigerian family planning clinic. Int J Womens Health. 2011;3:40913.

6. Badejoko OO, Bola-Oyebamiji S, Awowole IO, Salako AA, Ogunniyi SO. Urinary incontinence: prevalence, pattern, and opportunistic screening in Ile-Ife, Nigeria. Int Urogynecol J. 2016;27:269-73.

7. Ojengbede OA, Morhason-Bello IO, Adedokun BO, Okonkwo NS, Kolade CO. Prevalence and the associated trigger factors of urinary incontinence among 5000 black women in sub-Saharan Africa: findings from a community survey. BJU Int. 2011;107:1793-800.

8. Siddiqui NY, Levin PJ, Phadtare A, Pietrobon R, Ammarell N. Perceptions about female urinary 
incontinence: a systematic review. Int Urogynecol $\mathbf{J}$ 2014; 25: 863-871.

9. Mallah F, Montazeri A, Ghanbari Z, Tavoli A, Haghollahi F, Aziminekoo E. Effect of urinary incontinence on quality of life among Iranian women. J Family Reprod Health. 2014;8:13-9.

10. Akkus Y, Pinar G. Evaluation of the prevalence, type, severity, and risk factors of urinary incontinence and its impact on quality of life among women in Turkey. Int Urogynecol J. 2016;27:887893.

11. Zhu L, Lang J, Liu C, Han S, Huang J, Li X. The epidemiological study of women with urinary incontinence and risk factors for stress urinary incontinence in China. Menopause. 2009;16:831-6.

12. Obioha KC, Ugwu EO, Obi SN, Dim CC, Oguanuo TC. Prevalence and predictors of urinary/anal incontinence after vaginal delivery: prospective study of Nigerian women. Int Urogynecol $\mathrm{J}$. 2015;26:1347-54.
13. Padmanabhan $\mathrm{P}$, Dmochowski R. Urinary incontinence in women: a comprehensive review of the pathophysiology, diagnosis and treatment. Minerva Ginecol. 2014;66:469-78.

14. Demir O, Sen V, Irer B, Bozkurt O, Esen A. Prevalence and possible risk factors for urinary incontinence: a cohort study in the City of Izmir. Urologia Internationalis. 2017;99:84-90.

15. Mainuddin A, Ara Begum H, Rawal LB, Islam A, Shariful Islam SM. Women empowerment and its relation with health seeking behavior in Bangladesh. J Family Reprod Health. 2015;9:65-73.

Cite this article as: Njoku CO, Njoku AN, Emechebe CI, Okpe AE, Iklaki CI. Pattern and risk factors of non-fistulous urinary incontinence among gynaecological clinic attendees in a Nigeria tertiary health institution. Int J Reprod Contracept Obstet Gynecol 2020;9:2323-7. 